\title{
Impact of social networking sites on sleeping habits: A case of university students in Bangladesh
}

\author{
Mahabubur Rahman \\ University of Rajshhai, Bangladesh
}

DOI: 10.30547/worldofmedia.2.2019.4

\begin{abstract}
This study discusses the influences of social networking sites (SNSs) on the sleeping habits of students from two public universities in Bangladesh; until now, there hasn't been any study, which has looked into this issue in the context of students in Bangladesh. Primarily, the study is qualitative in nature, skillfully supplemented by quantitative data, collected through interviews (about 200) and focus group discussion (FGDs) (with about 48 participants). The findings of the study suggest that most of the students addicted to using social networking sites, sleep late into the night, indicating thereby that SNSs do have an impact on the traditional 'sleeping time', which in turn could be detrimental to the health and study of university students in Bangladesh.
\end{abstract}

\section{Keywords}

Social networking sites (SNSs), public university, sleeping habit, students, Bangladesh.

\section{Introduction}

Social networking sites (SNSs) have become a way of life today for the young populous around the world (Livingstone, 2002); in fact, they have attained a status of fundamental and inevitable medium for social interaction over the last decade for people, especially the youth, regardless of their caste, creed, social strata, etc. Social networking sites (SNSs) help nations and continents to connect, cutting across boundaries in ways, which until a few years ago seemed unthinkable, even to the most advanced researchers and academicians. Today, SNSs have more influence on our lives than we could ever imagine in contemporary years. According to a study on employer health benefits, conducted

Corresponding author:

Mahabubur Rahman, Department of Mass Communication and Journalism, University of Rajshhai, Rajshahi-6205, Bangladesh.E-mail: mcmahabub@gmail.com 
by the Kaiser Family Foundation and the Health Research \& Educational Trust (Kaiser/HRET, 2013), children from the age of three are able to operate mobile phones, frequently using mobile and internet technologies to play games online. It is estimated that on an average, teenagers in Western societies spend up to 7.5 hours on social media per day (Kaiser/HRET, 2013); as a matter of fact, teenagers today, are often referred to as the 'Facebook generation', implying that they use these SNSs excessively (Giannotti et al., 2012). However, the negative impact of social media on the mental and physical health of youth has been largely ignored in contemporary studies; in limited studies that are available, it has been found (Durlofsky, 2013; Flint, 2013) that youth across continents are suffering more from depression and insomnia due to the excessive use of social media (Kirk-Patrick \& Steijn, 2014).

Kirk-Patrick \& Steijn (2014) go on to state that SNSs are playing a significant role on the lifestyles of the youth, as they're oblivious to the negative impact of social media. Students form the largest social media user groups (Rahman, 2016) both across Western and Eastern societies, depending heavily on SNSs for their daily activities and communication (Rahman, 2016; Woods et al., 2016). Further, initially they hook onto these networks for various reasons, including chatting, gossiping, expressing views, cooperating, sharing ideas and information, entertainment, etc.; in fact, it is a source of refreshment for them (Ito et al., 2009). Just like the impact of ICT on students, guardians, academicians and researchers are anxious about the impact of SNSs on students' behavior and lifestyle. SNSs offers a new horizon to the researchers and academics to examine student's development and interaction through it. By analyzing this context, the present study focuses on the impact of SNSs on the sleeping habits of the university students of Bangladesh.

Rahman (2016) conducted a study entitled 'Youth participation in social networking sites (SNSs) in Bangladesh: A study on the changing patterns of communication, interpersonal relationship and its impact on personal life' from Bangladesh's perspective. The findings of the study indicate that university students report significantly worse quality of sleep, including inconsistent sleep schedules and sleep deprivation, than the general population; additionally, they also suffer from greater amount of daytime sleepiness, as there is a significant drop in their normal sleeping hours at night, which go on to affect their normal cognitive functioning (Rahman, 2016). Orzech et al. (2011) conducted a study entitled 'The state of sleep among college students at a large public university' from an American's perspective; they found that students tend to sacrifice night sleep to participate in social and academic commitments contributing constantly to changing sleep routines. All these factors in amalgamation do affect several 
crucial aspects of a university student's life, including the mood, functioning of the immune system, and even substance abuse (Orzech et al., 2011).

Though very few studies have been conducted about the relationship between students sleeping disorder and social media usage from the Western society's perspective (Shochat et al., 2014), there is hardly any study in the context of third world countries like Bangladesh; the present study therefore is an attempt to shed some light on this knowledge gap.

\section{Problem statement}

A study conducted by Levenson et al. (2016) found that $67 \%$ of young Americans aged between 19-29 are not getting ample time to sleep, tending thereby to impact their work activities during the day. Based on the same hypothesis, Rahman (2016) conducted a similar study for Bangladesh and found that almost fifty percent social media users of university students mentioned that Facebook has a negative effect on their sleeping behavior (Rahman, 2016). The present study is an attempt to uncover whether Facebook negatively influences the sleeping time of public university students of Bangladesh.

Levenson et al. (2016) conducted a study to investigate whether social media is related to sleep disorders of university students and found a highly positive correlation between the two; in concurrence to Levenson et al. study, there have been other studies too, which have affirmed that social media is indeed one of the most influential culprits in rising sleep disorders of university students, but these studies have been limited to the Western populous (Exelmans \& Van den Bulck, 2016; Levenson et al., 2016). Another study conducted by Christakis et al. (2011) between two student groups of Facebook users in the USA found that $90 \%$ of university students are virtually addicted to social media; further, their study affirmed that about $4 \%$ of total respondents surveyed have problematic or even addictive social media habits, affecting hazardously their sleep patterns and day-to-day lives. Exelmans \& Van den Bulck (2016) found that nine out of ten Americans between the age of 13 and 64 use social media before sleeping. Additionally, other researchers have also concurred with the fact that excessive use of Facebook is strongly associated with loss of sleep, irregular sleep-wake patterns, decreased quality of sleep, and increased fatigue during the daytime (Exelmans \& Van den Bulck, 2016). Woods \& Scott's (2016) study gave another dimension to this speculation - their study found that there is a strong relationship between social media use and anxiety, depression and low selfesteem, especially among adolescents and young adults.

Unfortunately, there is hardly any study found about the heavy uses of social media and sleeping disorder from Bangladesh's perspective. The purpose of the 
study is to determine whether social media use significantly affects sleeping patterns of university students, and whether social media impacts the usual sleeping time of the university students of Bangladesh.

\section{Literature review}

Shochat et al. (2014) propose that although the youth are spending a lot of time for learning and education, there is a large gap in research examining the interrelation of sleep and academic functioning and performance. Different studies (Brown et al., 2006, Chen et al., 2014; Hershner \& Chervin, 2014) suggest that there is indeed a connection between the quality of sleep and students' academic performance. Giannotti et al. (2002) found that due to the lack of proper sleeping habits, students suffer from depression and fatigue, as well as face difficulties with attention deficiency, concentration, decisionmaking abilities, memorizing and learning.

Orzech et al. (2011) found that there is a significant relationship between daytime sleepiness, decreased attention and concentration, which in turn, negatively impacts learning and memory recall in students. On the other hand, Milner \& Cote (2008) and Gomes et al. (2011) discussed how irregularities in the sleep schedule could affect a student's quality of sleep by delaying the body's natural circadian rhythm and homeostatic sleep drive.

Pantic (2012) conducted a study on 324 Serbian high school students and found that excessive use of SNSs could cause depression in different severities; out of the total respondents, $65 \%$ were found to have minimal depression, $29 \%$ had mild depression, and $6 \%$ had moderate depression. He concluded thereby that there is indeed a positive and significant correlation between the severity of depression vis a vis the time spent on SNS, wherein the degree of depression increased proportionately with the time spent on social networks. The study thereby clearly denotes that heavy dependency on SNSs does influence the level of depression among high school students.

Facebook is one of the most commonly used social media platforms; a study on Facebook users and their moods, conducted by the University of Michigan (2013), has shown that the more time people spend on Facebook, the more their happiness decreases. Interestingly, the aforementioned study clearly indicated that if a person spends more time on Facebook in daytime, his/her attitude worsens, and depression symptoms tend to creep in within some time. The findings of the study also suggest that after receiving negative comments or seeing other people post/pictures of good times or new purchases, may cause reduction of the students' self-esteem, which eventually could build up and lead to severe depression. 
Most of the heavy users of social media keep their smartphones next to them while sleeping (Rahman, 2016); this, not only acts as their alarm clocks, but also helps them in responding to important messages or calls at night; Bangladesh also is no exception in this regard (Rahman, 2016). According to a survey among the general populous within the USA, 50\% sleep with their phones and invariably wake up in the middle of the night to check their messages (Levenson et al., 2016), causing thereby serious sleep deprivation.

Yet in another study conducted by the Centre for Behavioral and Preventative Medicine, Miriam Hospital, USA (2013), one sees that extensive use of social media does result in lower academic performance in the long run, especially if the use of SNSs reduce the amount of sleep. As a matter of fact, this study had 483 first-year college female students who on an average were spending 12 hours a day on social media for chatting, commenting, browsing, posting, listening to music, etc.; this, in turn naturally impacted their grades. Thus, based on this finding, one could certainly confirm that extensive use of SNSs are well and truly associated with bad academic performance (Kirk-Patrick \& Roxanne, 2014).

By and large, the findings of the aforementioned studies indicate that there is a strong co-relationship between the social media usage habit and sleeping disorder, especially among students; however, as these research works have been limited to the Western context, the present study proposed to investigate the impact of Facebook on students' sleeping time in the context of Bangladesh.

\section{Objectives}

The main objective of the study is to find out the impact of SNSs on the sleeping time of public university students in Bangladesh. In line with the main objective, the proposed study has some specific objectives. These are:

1. To uncover the patterns of change in the sleeping time of public university students of Bangladesh.

2. To uncover the reasons of falling asleep late at night of the university students of Bangladesh.

3. To dig out a relationship of SNSs use late at night and sleepiness in class time of the university students of Bangladesh.

4. To uncover the relationship between heavy uses of SNSs and loneliness/ depression on typical days.

\section{Methodology}

Case-oriented qualitative research strategy (Ragin, 1997) has been applied to fulfill the objectives of the study. According to Yin (1994), the case study method 
is pertinent when an issue of research fulfills three most important criteria: first, minimum two questions in the form of what, why, and how have been posed. Second, the issue is a contemporary phenomenon. Third, the research will have no or little control over the respondents. From this perspective, the case study method has been chosen as being suitable for the present study.

The nature of the study is inductive. According to Goddard \& Melville (2004), the inductive approach starts with observations, and at the end of the research, theories or generalizations are formulated as a result of observations (Goddard \& Melville, 2004). Neuman (2003) affirms that beginning with detailed observations of the world inductive research moves towards more abstract generalizations and ideas (Neuman, 2003). Thus, an attempt has been made in this research to make a generalization about the impact of SNSs on the sleeping habit of public university students of Bangladesh, based on the findings of some specific target groups.

In order to find the impact of SNSs on student sleeping habits, two groups of students, namely SNSs user group (students who are using SNSs including Facebook) and SNSs non-user group (students who are not using any SNSs) have been created. To select the respondents, simple random sampling method has been applied. At first, the respondents were asked if they use SNSs including Facebook; the ones who responded in the affirmative were categorized in SNS user group, and those who said that they did not use SNSs, were categorized in non-user SNS group. This process continued until the entire targeted respondents were classified in one group or the other. Differences of sleeping habits between the two groups of students, along with problems relating to their sleeping habits helped the researcher determine the impact of SNSs on the sleeping habits of the university students of Bangladesh.

Two public universities (i.e. The University of Dhaka and the University of Rajshahi) were selected on the basis of purposive sampling. The main objective of selecting these two universities was solely for the purpose of having a representative sample; additionally, the University of Dhaka was selected as it is the oldest and largest university of Bangladesh, with student strength of about forty-five thousand. The University of Rajshahi was selected as it is the second oldest and largest university of Bangladesh, having almost thirty-seven thousand students (UGC, 2018). Both these reputed and oldest universities have students from all across the globe encompassing different religions, sex, race and ethnic identities (Rahman, 2016); thus, it is expected that both universities were just right in being able to represent public universities of Bangladesh today.

The researcher has chosen only Facebook for this study, as it is the most accepted and widely used social media platform used extensively by Bangladesh 
users (CNN, 2018; The Daily Star ${ }^{1}, 2018$ ). The total number of respondents was 200 (50x2x2). Hundred students (50 from each group) from each university have been selected based on simple random sampling method. Responses were voluntary. While selecting the sample, equal participation from both male and female students were ensured.

Both primary and secondary data have been used to look for an answer to the research questions. Primary data relevant to the objectives of the study, were collected through structured interviews (both open-ended and closeended) and focus group discussions (FGDs); secondary data were collected from different published and unpublished sources, i.e. published articles, books, periodicals, books, book chapters; manuals, unpublished dissertations and Internet browsing were used. To select secondary data sources for the present study, the qualification, reputation and experience of the researchers or research organizations has been considered. In order to evaluate the secondary data source for the present study, who presents the data and for what purpose it has been presented were considered. The source of the data presented, and the purpose for which the data has been presented have also been considered in order to use the secondary data.

Two sets of questionnaires were used to collect data from two different groups. According to the suggestion of Berger (2000), both open-ended and close-ended questions were included in the questionnaires. Four FGDs (two FGDs in each university with the user and non-user group) have been arranged with the respondents to cross-section the findings of the survey. The total participants in four FGDs were 48 (12 students in each FGD, 12X2X2 = 48).

\section{Findings and analysis}

The findings of the study (see Figure 1) indicates that, most of the students who are using SNSs sleep late at night in comparison to students who are not. $71.11 \%$ students from the user group prefer to sleep at late night, whereas only $15.55 \%$ respondents from the non-user group prefer to sleep late at night. On the other hand, $84.44 \%$ students from the non-user group prefer to sleep at night, whereas only $17.77 \%$ respondents from SNSs user group prefer to sleep at night. It indicates a significant difference in sleeping time between the user group and the non-user group.

\footnotetext{
${ }^{1}$ A highly circulated English daily in Bangladesh.
} 
Figure 1

\section{Usual sleeping time (both groups)}

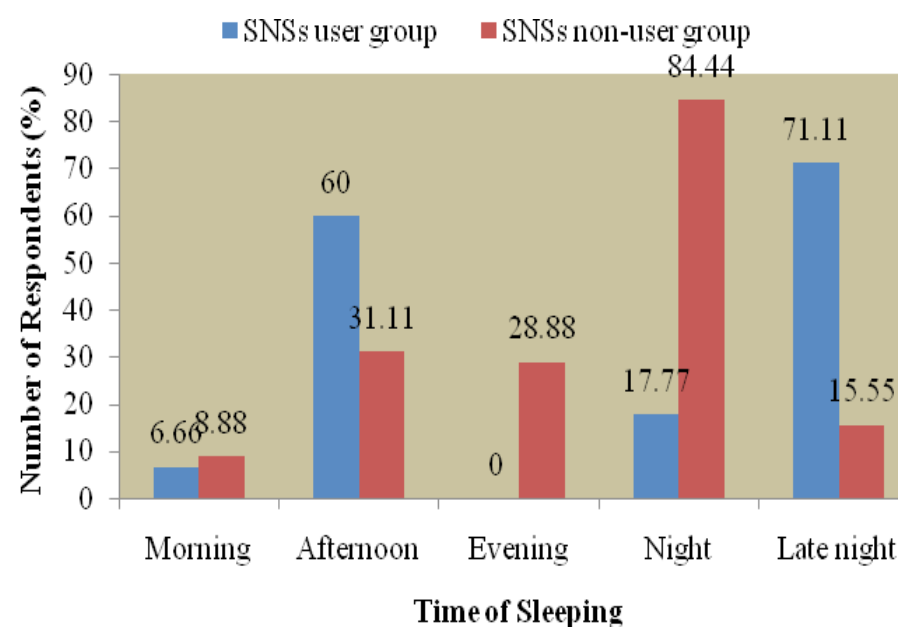

Source: interview data, 2018

Now the question is why a large number of students, heavily reliant on SNSs like to sleep late at night; Motahar Alam, a fourth-year student of the Department of Sociology, University of Dhaka, Bangladesh explains the same in the following way:

'Usually I sleep late at night because during the whole day I am engaged with my academic activities, cultural groups. In the evening I concentrate on my study. After 10 p.m. I join Facebook because most of my friends join Facebook after 10 p.m. The whole day I wait for this time as I get all types of information, entertainment from Facebook. I also get some academic information from my Facebook group. Normally, I go to bed at 3 a.m.-3.30 a.m.' (FGD, 2018).

According to Figure 2 (below), 51.11\% students of SNSs user group sleep 3-6 hours in a day, whereas 75.55\% SNSs non-user students sleep 3-6 hours. On the other hand, equal percent of students from both groups (24.44\%) sleep 6-9 hours in a day. The result indicates that students who are not using Facebook sleep more in comparison with the students who are using Facebook. 
Figure 2

\section{Usual sleeping hours (both groups)}

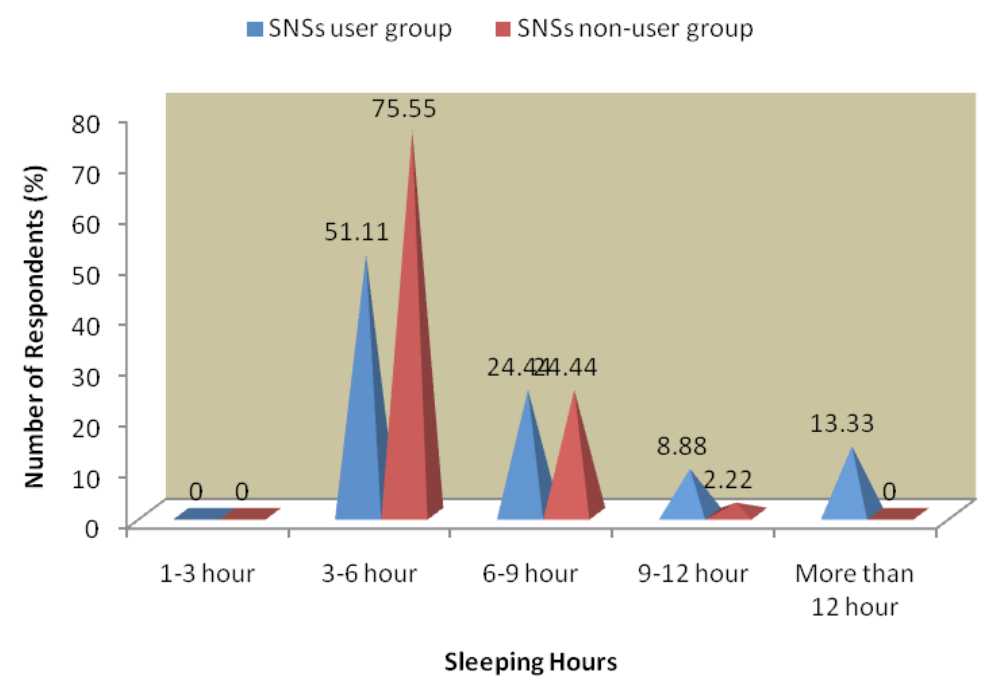

Source: interview data, 2018

Table 1 describes that, among 71.11\% users who sleep late at night, 53.33\% stated that they sleep late as they were using Facebook to socialize and connect; and $8.88 \%$ responded that they sleep late at night because of their studies. On the other hand, among the $15.55 \%$ non-users, $71.42 \%$ ensure that they sleep late because of study and $28.57 \%$ admit that they enjoy movie at night, and that is the reason for them to sleep late.

Table 1

Reasons of sleeping late (both groups)

\begin{tabular}{|c|c|c|c|c|c|}
\hline Reason & \multicolumn{2}{|c|}{ SNSs user group } & Reason & \multicolumn{2}{c|}{ SNSs non-user group } \\
\hline & Number & $\begin{array}{c}\text { Percentage } \\
(\%)\end{array}$ & & Number & $\begin{array}{c}\text { Percentage } \\
\text { (\%) }\end{array}$ \\
\hline Studying & 04 & 8.88 & Studying & 05 & 71.42 \\
\hline Gossiping & 03 & 6.66 & Gossiping & 00 & 00 \\
\hline Facebooking & 24 & 53.33 & Enjoying TV & 02 & 28.57 \\
\cline { 1 - 3 } Enjoying TV & 06 & 13.33 & Others & & 0.00 \\
\hline Others & 0 & 0.00 & & & \\
\hline
\end{tabular}

Source: interview data, 2018 
The result clearly indicates that there is indeed a correlation between sleeping late at night and browsing Facebook, especially among SNS users. Ahsan Mamun, a third-year student of the Department of English, University of Rajshahi talks about his reason of sleeping late at night:

'Generally, I used to go to bed at 12 a.m. in my childhood. After entering the University of Rajshahi, I have been living alone without my family. I have also been engaged in Facebook since my first year at the university. I don't like to spend time on Facebook in the afternoon or in the evening because of my studies and private tuition. That is why I like to join Facebook at midnight most of all. My bosom friend also spends time on Facebook after 12 p.m. As I don't read any newspapers, I get all necessary information regarding society and politics from Facebook. Because of browsing Facebook from midnight to late night I go to bed very late. I know this is not a good habit but now I am habituated with this routine. We (me and my friends) not only chat or gossip through Facebook, but also discuss different academic and socio-political issues through Facebook' (Interview data, 2018).

As shown in Figure 3, 60\% users confirm that Facebook adversely affects their sleeping time, and thus they think it is appropriate to change their 'Facebooking' habit. On the other hand, $40 \%$ students who are using Facebook, think that it does not make any difference to their sleeping time; their take is that it depends on individual users on how s/he will handle new media.

Figure 3

\section{Negative impact of Facebook on sleeping time (SNSs user group)}
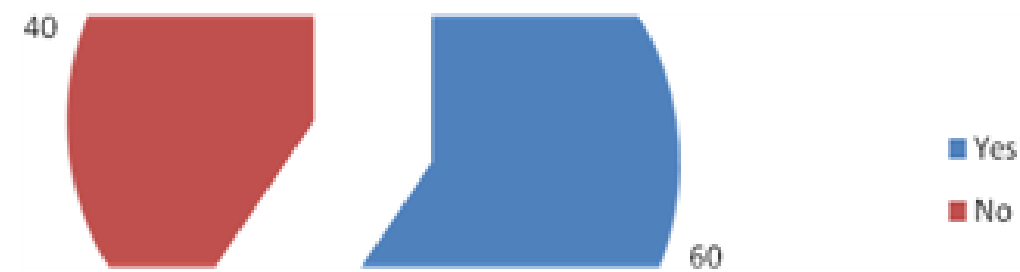

Source: interview data, 2018

Hasanur Kabir, a third-year student of the Department of Finance and Banking, University of Dhaka is one of those respondents who belong to this group. Being the topper of the class, while being a heavy user of Facebook, Hasan's feeling is different from other heavy users of Facebook. He expresses his feelings in the following way:

'I use Facebook heavily, but I can prioritize my work. I also use Facebook late at night, but it does not have any negative impact on my sleeping time. I sleep 
four to five hours at night and 2 hours in the afternoon. I was never late for my early morning classes or felt sleepy in the classroom' (FGD, 2018).

Researchers claim that, SNSs influence youth to stay at home rather than go outside as they can communicate with their friends from home. It has been found in a study that always staying at home make people lonely, which has an effect on sound sleep at night (Rahman, 2016). According to Table 2, 71\% students of SNSs user group feeling loneliness on typical days whereas $26 \%$ students from SNSs non-user group feeling loneliness on typical days. This finding also indicates a close relationship between late-night sleeping and felling loneliness on typical days.

Table 2

Feeling loneliness on typical days (both groups)

\begin{tabular}{|l|c|c|}
\hline \multicolumn{1}{|c|}{ Group } & Number & Percentage (\%) \\
\hline SNSs user group & 71 & $71 \%$ \\
\hline SNSs non-user group & 26 & $26 \%$ \\
\hline
\end{tabular}

Source: interview data, 2018

According to a study of 'Tempur' (a mattress company) (2010), people's sleeping patterns are significantly related with the reasons of insomnia (KirkPatrick \& Steijn, 2014). Ahsanul Haq (19), a third-year student of Department of Statistics, University of Rajshahi tends to feel very lonely on typical days and tried to illustrate the reasons of his loneliness. He said:

'I feel very lonely and depressed most of the days. I don't know the reason but when I browsed Facebook, I suffered from loneliness much more. Especially, when I found my friends posting their photographs with their girlfriends or found my friends enjoying quality time in restaurants and posting it depressed me a lot. I know because of the poverty of my family I don't have enough money to attend the party with my friends or enjoy quality time with my girlfriend. It hurts me a lot' (Interview data, 2018).

This finding correlates the findings of the study conducted by the University of Michigan (2013). But it is really tough to generalize this finding for the overall SNSs user students who are feeling loneliness or suffering from depression, because with heavy use of SNSs, some other social issues may be related with their loneliness or depression. Further research will be essential for the in-depth analysis of the issue. 
The study revealed that there is a significant interrelation between the usage of SNSs and sleepiness at class time. According to Figure 4, 87\% of heavy Facebook student users feel sleepy at class time, whereas 13\% students from Facebook non-user group feel sleepy at class time. It indicates that students who are using Facebook late at night feel sleepier in class. This finding corroborates with findings of other research works in Western societies where it has been found that social media has an effect on the sleeping time.

Figure 4

\title{
Sleepiness at class time
}

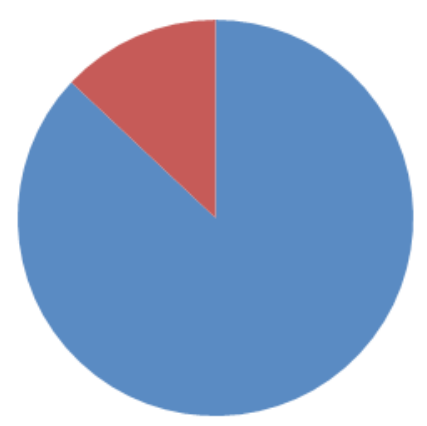

\author{
- Facebook user Group \\ - Facebook non-user \\ Group
}

Source: interview data, 2018

The findings of the present study reflect that there is a relationship between sleepiness at class time and late-night use of SNSs. We can consider here the story of Mohitul Alam, a third-year student of the Department of Accounting and Information System, University of Dhaka. Mohit says:

'I like to chat with my friends through Facebook. Some of my friends are living in the United States. The time difference between the United Sates and Bangladesh is almost twelve hours. So, when my friends return from their work it is almost late night here. That is why most of the time I go to bed at late night after chatting with them. Unfortunately, almost every day early morning I have classes in my department. Sometimes because of deep sleep I don't hear the alarm and miss the class. Sometimes I get up and attend the class but because of sleepiness I am unable to concentrate on the lecture' (FGD, 2018).

The results indicate that indulging with different SNSs like Facebook negatively affects the traditional sleeping schedule of students, which in turn could be detrimental to their health and study in the long run. The findings of Charlotte Kirk-Patrick \& Roxanne Steijn (2014) research support the 
aforementioned assumption partially. They found in their study that 3 million Facebook users of the UK had spent a week each in social media site when they had been in bed. That means average 21 minutes per day for a person. This has an impact of suffering from a sleep disorder such as insomnia. Dr. Hastings (2012) said about the impact of SNSs on sleep:

'From a sleeping point of view, this news isn't good at all as it's having a huge negative effect on people's sleep. The youth don't realise what impact using computers, mobile phones and other gadgets before falling sleep is having on their night's sleep. Being exposed to bright light from computers and mobile phone screens while in bed completely delays the brain and body's ability to get to sleep. As a result, people aren't able to fall sleep as quickly as they should $<\ldots>$ A lot of people think that when they go to sleep their brain is turned off $\langle\ldots>$ The brain simply engages in a different activity where it stores memories and gets rid of information that's not needed. If people aren't getting enough sleep each night, their long-term memory is most definitely being affected and using social networking sites and technology before they go to bed is worsening this'.

Researchers argued that computer-mediated communication (CMC) has bought some changes in every aspect of social lives, political culture, private lives or communal interaction (Nee, 2009; Tuffeckci, 2008). Researchers found that SNSs like Facebook has a significant impact on the regular life of the students (Acquisti \& Gross, 2006). A survey recently conducted at a high school in Cheshire, UK (2014), revealed that students use an average of 3-4 hours on SNSs every night, keeping in mind that they will miss something in their absence in social media. This is why students are getting tired and bored in the school activities, the study revealed.

Adan (2011) also found in his study that students who sleep less than 6 hours a day feel less interest in classes and studies. Some researchers of University of Pittsburgh (2018) found that youth who spend a lot of time on social media are more likely to suffer sleep disturbances. Thus, they summarize the findings of the study:

'We already know about the link between technology and sleep problems but not about the nature of social media and its unique association with sleep disturbances. Social media could affect sleep because of the light emitted from the screen, because the content is emotionally engaging or because people just get caught up doing it and go to bed later - or it could be a combination of all three'.

The scientific explanation of the relationship between SNSs and sleeping disorder could be found from Helen Driver (2018), a sonologist and assistant professor at Queen's University in Kingston, UK, wherein she says: 
'The explosion of social media and people staying on devices for longer and taking them to bed with them is a huge problem. The blue light emitted from your phone or tablet is over stimulating, despite special screens and other gimmicks that promise to minimize the effect'.

She also added: 'If you look at how a normal day goes, dawn is bluer light and dusk - when you should be going to bed - is warmer red light, which is less alerting' (Loney, 2018). And it's not just the light from your phone that is a sleep liability; it's the interactive nature of all devices and the overstimulation that comes with them.

This finding and analysis of the present study reflects other findings of the research works conducted in Western society perspective and clearly indicates the relationship between SNSs use in late night and sleepiness at class time.

\section{Conclusion}

In conclusion, it could be said that, SNSs have a definite effect on the sleeping habits of the university students of Bangladesh. It evidently influences the occurrence and severity of all types of sleeping disorder. Even though there are other factors that influence their sleeping habits, SNSs may certainly be a primary cause (Kirk-Patrick \& Steijn, 2014). Other factors, such as biological, environmental, psychological, and genetic ones, combined with SNSs, can impact the sleeping habits of the university students of Bangladesh. On the other hand, it has been found in this study that SNSs are negatively influencing students' sleep patterns, which also affect their academic engagement severely. Further, the result of the study indicates that SNSs impact negatively the sleeping habits of the university students of Bangladesh, which is indeed a critical factor causing sleeping disorders.

\section{References}

ASAD, S., MAMUN, M. A., \& CLEMENT, C. K. (2012). The effect of social networking sites to the lifestyles of teachers and students in higher educational institutions. International Journal of Basic and Applied Sciences, 1(4). Available from: https://www.sciencepubco.com/index.php/ijbas/article/ view/374 [Accessed 28th May 2018].

BAHAMMAM, A. S., ALASEEM, A. M., ALZAKRI, A. A., ALMENEESSIER, A. S., \& SHARIF, M. M. (2012). The relationships between sleep and wake habits and academic performance in medical students: A cross-sectional study. BMC Medical Education, 12. Available from: https://bmcmededuc.biomedcentral. com/articles/10.1186/1472-6920-12-61 [Accessed 11th April 2018]. 
BOYD, M. (2008). Why youth (heart) social network sites: The role of networked publics in teenage social life. In: D. Buckingham, Youth, identity, and digital media. Blackwell, USA.

CHEN, T., WU, Z., SHEN, Z., ZHANG, J., SHEN, X., \& LI, S. (2014). Sleep duration in Chinese adolescents: Biological, environmental, and behavioral predictors. Sleep Medicine, 15(11). Available from: https://www.ncbi.nlm.nih. gov/pubmed/25277663 [Accessed 18th August 2018].

CHRISTAKIS, D. A., MORENO, M. M., JELENCHICK, L., MYAING, M. T., \& ZHOU, C. (2011). Problematic Internet usage in US college students: A pilot study. BMCMedicine, 1(8). Available from: https://bmcmedicine.biomedcentral. com/articles/10.1186/1741-7015-9-77 [Accessed 12th March 2018].

DURLOFSKY, P. (2013). Can too much social media cause depression? PsychCentral, 8th July, 2018. Available from: https://psychcentral.com/blog/ can-too-much-social-media-cause-depression/ [Accessed 10th December 2018].

EXELMANS, L. \& VAN DEN BULCK, J. (2016). Bedtime mobile phone use and sleep in adults. Social Science \& Medicine, 148. Available from: https:// www.ncbi.nlm.nih.gov/pubmed/26688552 [Accessed 23rd June 2018].

FERREIRA, L. R. C. \& MARTINO, M. M. F. D. (2012). Sleep patterns and fatigue of nursing students who work. Revista da Escola de Enfermagem da USP, 46(5).

FLINT, L. (2013). How does social media as a technology affect sleeping patterns? Available from: https://insomniainnovation.wordpress. com/2013/04/26/how-does-social-media-as-a-technology-affect-sleepingpatterns/ [Accessed 23rd May 2018].

FOX, J. (2005). The R Commander: A basic statistics graphical user interface to R.' Journal of Statistical Software, 14(9). Available from: https://www. jstatsoft.org/article/view/v014i09 [Accessed 7th May 2018].

FRANKLIN, C. B., WALTER, C. B., \& BARLOW, S. (2006). Development and evaluation of the sleep treatment and education program for students (STEPS). Journal of American College Health, 54(4). Available from: https://www.ncbi. nlm.nih.gov/pubmed/16450848 [Accessed 19th April 2018].

GIANNOTTI, F., CORTESI, F., SEBASTIANI, T., \& OTTAVIANO, S. (2002). Circadian preference, sleep and daytime behaviors in adolescence. Journal of Sleep Research, 11(3). Available from: https://www.ncbi.nlm.nih.gov/ pubmed/12220314 [Accessed 24th March 2018].

GODDARD, W. \& MELVILLE, S. (2004). Research methodology: An introduction. Blackwell Publishing.

GOMES, A. A., TAVARES, J., \& AZEVEDO DE M. P. (2011). Sleep and academic performance in undergraduates: A multi-measure, multi-predictor 
approach. Chronobiology International, 28(9). Available from: https://www. ncbi.nlm.nih.gov/pubmed/22080785 [Accessed 23rd April 2018].

HARDIE, E. \& TEE, M. Y. (2007). Excessive Internet use: The role of personality, loneliness and social support networks in Internet addiction. Society, 5(1). Available from: http://hdl.handle.net/1959.3/5548 [Accessed 2nd March 2018].

HERSHNER, S. D. \& CHERVIN, R. D. (2014). Causes and consequences of sleepiness among college students. Nature and Science of Sleep, 6. Available from: https://www.ncbi.nlm.nih.gov/pmc/articles/PMC4075951/ [Accessed 15th March 2018].

KIRK-PATRICK, C. \& STEIJN, R. (2014). How much of an effect does social media have on insomnia and depression? Research Paper based on lectures at the Medlink Workshop Conferences at Nottingham University. Available from: https://medlink-uk.net/wp-content/uploads/2014/11/Kirk-PatrickCSteijnR. pdf [Accessed 10th December 2018].

LEVENSON, J. C., SHENSA, A., SIDANI, J. E., COLDITZ, J. B., \& PRIMACK, B. A. (2016). The association between social media use and sleep disturbance among young adults. Preventive Medicine, 85. Available from: https://www.ncbi.nlm. nih.gov/pubmed/26791323 [Accessed 17th March 2018].

LONEY, S. (2018). How social media is ruining your sleep. Reader's Digest Best Health. Available from: http://www.besthealthmag.ca/best-you/sleep/ social-media-affects-sleep/ [Accessed 21st May 2018].

LOVATO, N., LACK, L., \& WRIGHT, H. (2014). The napping behavior of Australian university students. PLoS One, 9(11). Available from: https://www. ncbi.nlm.nih.gov/pubmed/25412257 [Accessed 12th April 2018].

MILNER, C. E. \& COTE, K. A. (2009). Benefits of napping in healthy adults: Impact of nap length, time of day, age, and experience with napping. Journal of Sleep Research, 18(2). Available from: https://www.ncbi.nlm.nih.gov/ pubmed/19645971 [Accessed 28th May 2018].

NEUMAN, W. L. (2003). Social research methods: Qualitative and quantitative approaches. Allyn and Bacon.

ORZECH, K. M., SALAFSKY, D. B., \& HAMILTON, L. A. (2011). The state of sleep among college students at a large public university. Journal of American College Health, 59(7). Available from: https://www.ncbi.nlm.nih.gov/ pubmed/21823956 [Accessed 1st June 2018].

ORZECH, K. M., GRANDNER, M. A., ROANE, B. M., \& CARSKADON, M. A. (2016). Digital media use in the $2 \mathrm{~h}$ before bedtime is associated with sleep variables in university students. Computers in Human Behavior. Available from: https://www.ncbi.nlm.nih.gov/pmc/articles/PMC5279707/ [Accessed 13th January 2018]. 
PANTIC, I., ALEKSANDAR, D., JOVANA, T., DUBRAVKA, T., DRAGANA, B. J., SINISA, R., \& SENKA, P. (2012). Association between online social networking and depression in high school students: Behavioral physiology viewpoint. Psychiatria Danubina, 24(1). Available from: https://www.ncbi.nlm.nih.gov/ pubmed/22447092 [Accessed 4th April 2018].

RAGIN, C. C. (1997). Turning the tables: How case-oriented research challenges variable-oriented research. Comparative Social Research, 16.

ROBINSON, D., GELAYE, B., TADESSE, M. G., WILLIAMS, M. A., LEMMA, S., \& BERHANE, Y. (2013). Daytime sleepiness, circadian preference, caffeine consumption and Khat use among college students in Ethiopia. Journal of Sleep Disorders Treatment \& Care, 3(1). Available from: https://www.ncbi.nlm.nih. gov/pmc/articles/PMC4015623/ [Accessed 26th May 2018].

SEXTON-RADEK, K. \& HARTLEY, A. (2013). College residential sleep environment. Psychological Reports, 113(3). Available from: https://www.ncbi. nlm.nih.gov/pubmed/24693819 [Accessed 13th March 2018].

SHOCHAT, T., COHEN-ZION, M., \& TZISCHINSKY, O. (2014). Functional consequences of inadequate sleep in adolescents: A systematic review. Sleep Medicine Reviews, 18(1). Available from: https://www.ncbi.nlm.nih.gov/ pubmed/23806891 [Accessed 25th May 2018].

Student grades not affected by social networking. Newswise, 23rd December, 2009. Available from: http://www.newswise.com/articles/student-grades-notaffected-by-social-networking-new-research-finds [Accessed 12th August 2018].

The Daily Star, 30th May, 2018.

The Kaiser Family Foundation and Health, Research and Education Trust (2013). Employer health \& benefits annual survey. Available from: https:// kaiserfamilyfoundation.files.wordpress.com/2013/08/8465-employer-healthbenefits-20131.pdf [Accessed 16th April 2018].

WALKER, M. P., BRAKEFIELD, T., MORGAN, A., HOBSON, \& J. A., STICKGOLD, R. (2002). Practice with sleep makes perfect: Sleep-dependent motor skill learning. Neuron, 35(1). Available from: https://www.ncbi.nlm.nih. gov/pubmed/12123620 [Accessed 14th June 2018].

WOLNICZAK, I., CÁCERES-DELAGUILA, J. A., PALMA-ARDILES, G., ARROYO, K. J., SOLÍS-VISSCHER, R., PAREDES-YAURI, S., \& BERNABEORTIZ, A. (2013). Association between Facebook dependence and poor sleep quality: A study in a sample of undergraduate students in Peru. Available from: https://journals.plos.org/plosone/article?id=10.1371/journal.pone.0059087 [Accessed 28th March 2018].

WOODS, H. C. \& SCOTT, H. (2016). \#Sleepyteens: Social media use in adolescence is associated with poor sleep quality, anxiety, depression and low 
self-esteem. Journal of Adolescence, 51. Available from: https://www.ncbi.nlm. nih.gov/pubmed/27294324 [Accessed 17th March 2018].

XANIDIS, N. \& BRIGNELL, C. M. (2016). The association between the use of social network sites, sleep quality and cognitive function during the day. Available from: http://eprints.gla.ac.uk/169556/ [Accessed 28th March 2018]. YIN, K. R. (1994). Case study research design and methods. California, Sage Publications. 